pushcart of bananas".

Wensberg portrays Land as two personalities: as an extrovert he presided at the annual meetings of Polaroid stockholders, which were extravaganzas touting his latest (and invariably best) invention, complete with hyperbole and hoopla; but on the personal level, he is diffident and retiring - even reclusive at least to outsiders.

In writing the book, Wensberg pored over letters and speeches by Land and material from Polaroid annual reports, and collected anecdotes and reminiscences from Land's colleagues and friends. Wensberg narrates key events in Land's life - using so-called "new journalism" techniques - by reconstructing
Land's thoughts and words in conversation. "There are some of Land's words in those stories", he says; "I confess to having enlarged upon them". The prospect of reading reconstructed quotations attributed to him drives Land up the wall: "That's a terrible indignity", he is reported to have said, "I always thought quotation marks were a sacred signal of meticulous honesty".

Honest or not, these "corroborative details add artistic verisimilitude" to a fascinating account of Edwin Land's remarkable achievements.

John N. Howard, 7 Norman Road, Newton Highlands, Massachusetts 02161, USA, is Editor Emeritus of Applied Optics, and also Editor of Optics News, both journals of the Optical Society of America.

\section{Logical conclusions}

\section{Philip Kitcher}

Quiddities: An Intermittently Philosophical Dictionary. By W.V. Quine. Harvard University Press: 1987. Pp. 249. $\$ 20, £ 15.95$.

OVER half a century ago, a young Harvard professor of logic and philosophy published an article expressing doubts about some of the central themes of logical positivism, then in the flush of its new dominance of the Anglo-Saxon philosophical world. That article, "Truth By Convention", was to begin a series of explorations and critiques that would decisively alter philosophical views about logic, mathematics, language and science. Its author, W.V. Quine, would become the dominant figure in post-war Englishlanguage philosophy, first in the United States, and later in England, Scandinavia and Australia. Just as Quine is quoted on the back of the abridgement of the classic Principia Mathematica of Whitehead and Russell - "This is the book that has meant the most to me" - so generations of philosophical logicians, philosophers of language and philosophers can testify that some essay, collection or book of Quine's has been the decisive influence on their own professional researches.

Quiddities is the work of an author who has faith in his own idiosyncratic enthusiasms. Ranging from lucid expositions of philosophical topics that are central to the fields that have intrigued him throughout his career - particularly logic and the philosophy of mathematics - to entertaining and informative details about the quirks of natural languages, it fuses wit with instruction. Fundamental aspects of twentieth-century logic and set theory are explained in ways that will be comprehensible to beginners (while whetting their appetites for further details) and that will be satisfying to the initiated. Quine's

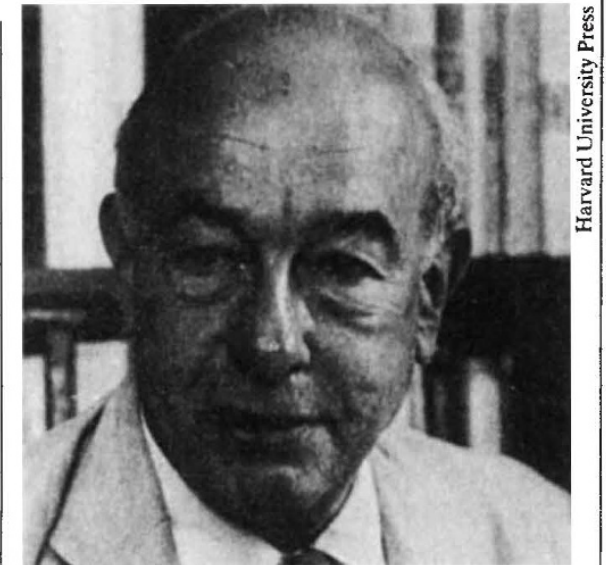

W.V. Quine - idiosyncratic enthusiasms.

talents for exposition are amply displayed in articles on familiar Quinean topics: classes versus properties, classes versus sets, definition, Gödel's theorem, identity, impredicativity, infinite numbers, natural numbers, paradoxes, predicate logic, reference and reification, singular terms, truth, universals, use versus mention, variables. For those who are unaware of the achievements of modern logic, this sequence of articles offers a beautiful presentation of the main staples of contemporary logic, as attractive as it is nourishing.

Perhaps the chief delight of Quiddities lies in the tidbits that are sprinkled throughout the menu. Quine has always been entertained by ordinary language, by the odd relationships among words in different languages, by the ways in which languages change, and the scraps and vestiges that are left behind. Quiddities reveals some of the learning that a lifetime's fascination with words can produce. Readers may be surprised to learn how the violoncello got its name, intrigued by the possibility of using inflections to build ever more complex Latin verbs, struck by Quine's demonstrations that gender in language can sometimes be used to disambiguate and can sometimes lead to intra-linguistic tension, and frankly repentant about their past usages of 'agenda' and 'media' (both are Latin plurals corrupted as singulars). Quine wears his learning lightly, and the grace of his discussions reflects his love of the whimsy of language.

Quiddities is an "intermittently philosophical dictionary" in two senses. Not only is the philosophy punctuated by articles on matters linguistic, but the treatment of philosophical issues is itself quite selective. There are only occasional ventures into philosophical territory that Quine has not explored in his more academic writings, and these ventures seem to me rather disappointing. For example, in discussing the hoary topic of free will, Quine, like many other philosophers, favours the view that freedom is compatible with psychological determinism. Though all our actions and decisions may be completely caused, that does not necessarily deprive us of freedom. What matters is the way in which they are caused. One who adopts this view must explain what kind of causation allows for freedom, and it is in discharging this task that Quine seems to me to go astray.

David Hume offered the simplest account: we act freely when our actions are caused by our beliefs and desires. Yet it has seemed to numerous philosophers that this is far too simple, for there are individuals who are compelled by their desires - kleptomaniacs, alcoholics, compulsive smokers - and, though they satisfy their desires, they do not act freely. Another condition must be satisified to ensure freedom, a condition that will differentiate those who are psychologically disabled from those whose considered desires are manifested in their behaviour.

Quine has no time for such complications. He offers the original Humean solution, and, in response to the possibility of "ill health of the offender's decisionmaking faculties", declares that psychological disability can provide no excusing grounds. This blunt treatment of the problems has the advantage of simplicity, but it surely errs in overlooking the existence of coercion from within as well as from without. Moreover, in explicitly frowning on the use of insanity pleas, it runs the risk of supporting much injustice.

Ultimately, though, questions of freedom, morality and punishment are not at the centre of Quine's thought. For many readers, Quiddities will serve as a superb introduction to central issues in contemporary thinking about logic, mathematics, language and science, an introduction that may lead them on to appreciation of Quine's half century of seminal writings. Aficionados will enjoy the witty reformulations of familiar themes and find a bonus in learning about the quintessential quirkiness of natural language.

Philip Kitcher is a Professor in the Department of Philosophy, University of California, San Diego, La Jolla, California 92093, USA. 